

\section{Sumário}

ATIVISMO JUDICIAL E CONTROLE DE POLÍtICAS PÚBLICAS........................................................14 Rodrigo Monteiro da Silva

JuRisdição Voluntária No CPC/2015 COMO MEIO DE RESOluÇão DE 'CONTROVÉRSIAS' COM A AdministraÇão PÚBliCA ....................................................................................................29

Jefferson Carús Guedes

A MEDiaÇão COMUNitÁRIA COMO FERRAMENTA DE ACESSO A JUSTIÇA E DESENVOLVIMENTO NO

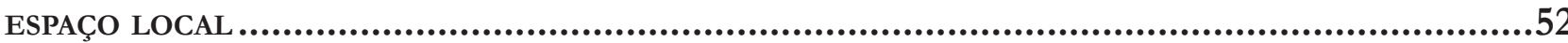

Daniela Arguilar Camargo

LEGITIMIDADE CONSTITUCIONAL DA ATUAÇÃO INTERNACIONAL DOS MUNICÍPIOS BRASILEIROS: UMA Leitura À lUZ DA TEORia DA Constituição Dirigente .65

Regina Claudia Laisner e Danilo Garnica Simini

JUdiCIALIZAÇão DE POLÍTICAS PÚbliCAS EM PROL DOS ANIMAIS: UMA VISÃo DE SAÚDE ÚNICA ....84 Luiz Gustavo Gonçalves Ribeiro e Clarice Gomes Marotta

JudicializAÇão DA SAÚDE, ATIVISMO JUDICIAL E O CONSEQUENTE DESEQUILÍBRIO DO ORÇAMENTO PÚBLICO

Juvêncio Borges Silva e João Paulo Jucatelli

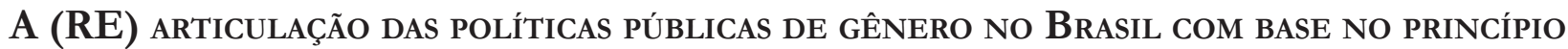
JURÍDICO DA SUBSIDIARIEDADE E DA DESCENTRALIZAÇÃO 117

Tamiris Alessandra Gervasoni e Marli Marlene Moraes da Costa

Desenvolvimento sustentável, educação e democracia: o caso

"Escola Sem Partido" 134

Veyzon Campos Muniz

Políticas de aCesso aberto para trabalhos CiENTíficos: INTERESSE PÚblico E DiReitos De AUTOR

Eduardo Altomare Ariente 
Financiamento CUltural no Brasil CONTEMPORÂNEO 172

Frederico Augusto Barbosa da Silva

Naturaleza y Constitución 193

Livio Perra

REGULAÇÃO AMBIENTAL DA ATIVIDADE MINERÁRIA: UMA ANÁLISE ECONÔMICA DE COMPLIANCE 208

Lorena Machado Rogedo Bastianetto e Magno Federici Gomes

O NEODESENVOLVIMENTISMO E A QUESTÃo AMBIENTAL: O PAPEL DA HIDROELETRICIDADE NO SISTEMA ENERGÉTICO BRASILEIRO.

Andreza Aparecida Franco Câmara

O COMPARTILHAMENTO DE DADOS E INFORMAÇÕES PESSOAIS DE CONSUMIDORES: O ABUSO DOS FORNECEDORES E AS PROPOSTAS APRESENTADAS NO PLS 181/2014 .................................247 Héctor Valverde Santana e Rafael Souza Viana

UTILIZAÇÃO DA COMPUTAÇÃO EM NUVEM NO PODER LEGISLATIVO: PERCEPÇÕES DOS GESTORES E

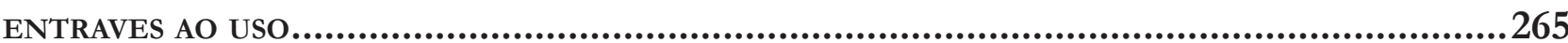
Igor Vinicius de Lucena Diniz, Lucas dos Santos Costa e Marcos Fernando M. Medeiros

O PROCESSO PENAL E A ENGENHARIA DE CONTROLE DA POLÍtTICA CRIMINAL Antonio Henrique Graciano Suxberger e José Wilson Ferreira Lima

Gestão de Presídios por Parcerias Público-Privadas: uma análise das atividades passíVEIS DE DELEGAÇÃO 305

Fernando Borges Mânica e Rafaella Brustolin 


\title{
Regulação ambiental da atividade minerária: uma análise econômica de compliance*
}

\section{Environmental regulation on mining: an economic analysis of compliance}

\author{
Lorena Machado Rogedo Bastianetto** \\ Magno Federici Gomes***
}

\section{Resumo}

Este trabalho foca-se no estudo da sistemática de regulação ambiental brasileira voltada para a atividade de mineração. Ao se valer da vertente metodológica jurídico-dogmática e do raciocínio lógico-dedutivo, procura-se delinear os aspectos de influência mais relevantes na concretização dos objetivos da atividade regulatória, quais sejam: participação dos atores sociais na formação da norma, compliance, fiscalização indireta, monitoramento contínuo e governança ambiental. A economia comportamental e as políticas públicas regulatórias são o cerne do trabalho para a compreensão das razões de sucesso ou colapso da performance regulatória. No desfecho, busca-se maior reflexividade acerca do processo normativo, sugerindo-se a construção de um critério legítimo para nomeação de conselheiros e a criação de mecanismos de abertura do conselho regulador à participatividade difusa.

* Recebido em 13/03/2017 Aprovado em 11/04/2017

** Doutoranda em Direito Processual pela PUC Minas. Mestre em Direito Ambiental e Desenvolvimento Sustentável pela Escola Superior Dom Helder Câmara/BH. Pós-graduada em Direito Processual pela PUC Minas. Treinada em Direito Alemão e Europeu/Ludwig - Maximilians - Universität/Munique/Alemanha. Pósgraduada em Gestão Empresarial/Fundação Getúlio Vargas/IBS. Graduada em Direito pela Universidade Federal de Minas Gerais.

*** Pós-doutor em Direito Público e Educação pela Universidade Nova de Lisboa-Portugal. Pós-doutor em Direito Civil e Processual Civil, Doutor em Direito e Mestre em Direito Processual, pela Universidad de Deusto-Espanha. Mestre em Educação pela PUC Minas. Professor do Mestrado Acadêmico em Direito Ambiental e Sustentabilidade na Escola Superior Dom Helder Câmara. Professor Adjunto da PUC Minas e Professor Titular licenciado da Faculdade de Direito Arnaldo Janssen. Advogado Sócio do Escritório Raffaele \& Federici Advocacia Associada. Integrante dos grupos de pesquisa: Regulação Ambiental da Atividade Econômica Sustentável (REGA)/CNPQ-BRA e Centro de Investigação \& Desenvolvimento sobre Direito e Sociedade (CEDIS)/FCT-PT. ORCID.
Palavras-chave: Sistema regulatório. Meio ambiente. Mineração. Economia comportamental. Regulação responsiva.

\section{Abstract}

This article focuses on the study of Brazilian environmental regulatory system on mining activities. Based on the juridical dogmatic alignment and deductive reasoning, it depicts the most influential aspects of the regulatory activity in pursuit of its objectives, such as: participation in norm formation, compliance, indirect monitoring, continuos controlling and environmental governance. Behavioral economics and regulatory public policies are the keys of this study in order to perceive the reasons of success or collapse of the regulatory performance. In conclusion, it is aimed a broader reflection on norm-making process, suggesting the construction of a legitimate criterion for appointment of directors and the creation of mechanisms for opening the regulatory council to diffuse participation.

Keywords: Regulatory System. Environment. Mining. Behavioral Economics. Responsive Regulation. 


\section{INTRODUÇÃO}

A mineração é uma atividade econômica de grande relevância na arquitetura constitucional nacional. Ao se estatuir a dominialidade pública una e a competência legislativa concentrada da União em relação aos minerais ${ }^{1}$, em que quer que se encontrem, capta-se a carga valorativa das normas atributivas. $O$ vulto meritório das disposições constitucionais em apreço possui estrita simetria com a soberania e o desenvolvimento da sociedade brasileira ${ }^{2}$, dado que não infirma a eminência outorgada ao meio ambiente ecologicamente equilibrado e ao primado de defesa ambiental para o desenvolvimento da atividade econômica ${ }^{3}$.

Nesse contexto, a convergência dos regimes de aproveitamento dos minerais administrados pela União ${ }^{4}$ e dos procedimentos administrativos de licenciamento ambiental, de competência comum dos três entes da Federação ${ }^{5}$, é uma opção política do poder constituinte brasileiro, tecendo uma gestão pública disjuntiva da atividade mineradora.

A atividade regulatória nacional possui laços estreitos com as políticas públicas de Estado e, em se tratando de mineração, as características intrínsecas à exploração desses recursos como a rigidez locacional e a raridade, associadas à saliente dependência da comunidade global aos minerais, corolário da indispensabilidade do recurso mineral ${ }^{6}$, são considerações essenciais para a atividade legislativa intensa dos entes federados, visando à mitigação das externalidades ambientais negativas de toda ordem, bem como ao prolongamento da longevidade mineral.

Faz-se importante salientar que a cessão constitucional da dominialidade mineral à União impõe a esta, claramente, o encargo de disponibilizar esse recurso à população brasileira, pessoas naturais e entes morais, bem como o ônus de administrar os recursos sob uma perspectiva sustentável. Essa incumbência de administração sustentável, no entanto, não cabe, apenas, à União, é pulverizada tanto entre os entes da Federação ${ }^{7}$ quanto entre a sociedade civil ${ }^{8}$.

A repartição constitucional de responsabilidade entre os atores da sociedade brasileira deve refletir sobre o programa de políticas públicas inserto na regulação ambiental, peculiaridade substancial para a elaboração de um gerenciamento público concomitantemente mais enxuto e mais eficaz, hábil a garantir o interesse nacional no aproveitamento mineral, corrigir as distorções da economia de livre-mercado e a maximizar a fiscalização socioambiental indireta da atividade mineira. O recrudescimento do monitoramento indireto, entendido como aquele empreendido pela própria iniciativa privada, pelo terceiro setor e pela população em geral por meio das políticas públicas regulatórias, é a viga mestra da responsabilidade compartilhada responsiva ${ }^{9}$, ideação crucial na redução dos custos e encargos do Estado brasileiro.

Nessa conjuntura, este trabalho teórico-documental, a partir da metodologia jurídico-dogmática e do raciocínio lógico-dedutivo, alicerça-se no estudo econômico-comportamental do sistema regulatório ambiental brasileiro voltado à atividade minerária. Analisa-se a política ambiental de ingerência na atividade minerária no intento de aprimoramento do discernimento da funcionalidade e sustentação do aparato normativo contemporâneo.

1 A respeito, consultar: art. 20, inciso IX, e art. 22, inciso XII, da Constituição da República de 1988 (CR/1988).

2 A respeito, consultar: art. $3^{\circ}$, inciso II, e art. 170, inciso I, da CR/1988.

3 A respeito, consultar: art. 225 e art. 170, inciso VI, da CR/1988.

4 A respeito, consultar: art. $1^{\circ}$ e $2^{\circ}$ do Decreto-Lei n ${ }^{\circ} 227 / 1967$.

5 A respeito, consultar arts. $7^{\circ}$, inciso XIII, $\$ 8^{\circ}$, inciso XIII e $\$ 9^{\circ}$, inciso XIII, da Lei Complementar (LC) $\mathrm{n}^{\circ} 140 / 2011$.

6 Os traços marcantes da mineração encontram-se em: SERRA, Silvia Helena; ESTEVES, Cristina Campos. Mineração: doutrina, jurisprudência, legislação e regulação setorial. São Paulo: Saraiva, 2012. p. 42. (Col. Direito Econômico).

7 A título exemplificativo, consultar: art. 23, incisos III, IV, V, VI, VII, IX, X, XI, XII, da CR/1988.

8 A título exemplificativo, consultar: art. 225 da CR/1988.

9 A expressão "regulação responsiva” é de AYRES, Ian; BRAITHWAITE, John. Responsive regulation. Transcending the deregulation debate. New York, NY: Oxford University, 1992. p. 16-19. 
As pesquisas de Ayres e Braithwaite ${ }^{10}$ e Sunstein ${ }^{11}$ sobre regulação pública são o eixo principal deste artigo, que tem por objetivo ressaltar a premente necessidade de revisões e reconsiderações da relação entre o setor público e privado ${ }^{12}$, seus comportamentos intuitivos e motivacionais, bem como a imperiosa participatividade do cidadão e do empresariado para o bom desempenho do sistema regulatório nacional. No desfecho, realça-se uma visão reflexiva de governança ambiental como política pública para o exercício do serviço público de tomada de decisão normativa.

O estudo inicia-se com o exame do fenômeno regulatório, sua performance e o posicionamento dos agentes públicos, econômicos e da população em geral no processo regulatório. Em seguida, analisa-se a lógica publicista para a construção e estabelecimento do sistema normativo ambiental. Por sua vez, o panorama privatístico acerca da formação e concretude da regulação é destacado com o propósito de identificação dos principais fatores de sucesso ou falência do sistema. Por fim, destacam-se as perspectivas pública e privada para a ampliação dos enfoques do fenômeno regulatório ambiental.

\section{O SISTEMA REGULATÓRIO BRASILEIRO APLICADO À MINERAÇÃO: CONCEPÇÕES CONTEMPORÂNEAS}

Classicamente, o termo "regulação" imprime a compreensão de verticalização em uma relação hostil, ou seja, o Estado, por meio de seu poder interventivo na atividade econômica, estabelece normas e restrições à liberdade performática da iniciativa privada, e esta, posicionando-se na extremidade inferior, é receptora dessa normatização e, ao mesmo tempo, contentora das imposições públicas sobre questões que concebe, predominantemente, privadas.

Há muito, sabe-se que essa disposição hierárquica é falaciosa. Incontestável é, no entanto, que o fluxo regulatório nacional é intenso no que concerne à atividade de mineração. Como já exposto acima, o exercício da atividade mineira no Brasil é controlado pelo Departamento Nacional de Produção Mineral (DNPM) ${ }^{13}$, autarquia federal aglutinadora tanto das competências de fiscalização e controle da atividade, bem como da própria outorga do direito de minerar. Paralelamente, os demais entes federativos empreendem, também, o poder de polícia de registro, acompanhamento e fiscalização do aproveitamento mineral em seus territórios $^{14}$, assim como legislam e promovem as políticas públicas pertinentes à proteção ao meio ambiente ${ }^{15}$.

Concomitantemente a essa arquitetura regulatória pública, a iniciativa privada mineira global tem se organizado, institucionalmente, no intento de aprimorar suas práticas internas, fomentar a pesquisa, o desenvolvimento tecnológico e econômico, a sustentabilidade ${ }^{16}$ e, principalmente, de esforçar-se para reduzir os fossos e desníveis nas práticas empresarias voltadas às externalidades da atividade de mineração ${ }^{17}$. Essa institucionalização do segundo setor é, na verdade, nada mais que uma fonte formal autônoma de regulação,

10 AYRES, Ian; BRAITHWAITE, John. Responsive regulation. Transcending the deregulation debate. New York, NY: Oxford University, 1992. p. 16-19.

11 Ver: SUNSTEIN, Cass R. Simpler: the future of government. New York, NY: Simon and Schuster, 2014.

12 A respeito da mitigação de barreiras entre o público e privado, consultar: SOLOMON, Jason M. New governance, Preemptive self-regulation, and the blurring boundaries in regulatory theory and practice. Wisconsin Law Review, Madison-USA, p. 9-69, jul. 2010.

13 A respeito das competências do DNPM, consultar: art. $3^{\circ}$ da Lei $n^{\circ} 8.876 / 1994$; art. $2^{\circ}$ e $3^{\circ}$, \$2 $2^{\circ}$ do Decreto-Lei ${ }^{\circ} 227 / 1967$.

14 A respeito da competência administrativa constitucional dos demais entes da Federação, consultar: art. 23, inciso XI, da CR/1988.

15 A competência legislativa dos demais entes em matéria ambiental encontra-se no art. 24, incisos VI e VII; e art. 30, incisos I, II, da CR/1988.

16 Para analisar a ideia de desenvolvimento econômico em contraposição ao desenvolvimento sustentável e estudar um caso concreto, ver: BIZAWU, Kiwonghi; GOMES, Magno Federici. Oil exploitation at Virunga park as a threat to the environment and to endangered animal species. Veredas do Direito, Belo Horizonte, v. 13, n. 27, p. 11-29, set./dez. 2016. p. 18-21.

17 A institucionalização da atividade mineira é exemplificada pelo Instituto Brasileiro de Mineração (IBRAM); e pelo Conselho Internacional de Mineração e Metais (ICMM). 
muito comum no Direito do trabalho brasileiro por meio das convenções e acordos coletivos, bem como por intermédio dos regulamentos internos das corporações ${ }^{18}$.

Os estudos de economia comportamental de Sunstein ${ }^{19}$ e de regulação responsiva de Ayres e Braithwaite ${ }^{20}$ proporcionam a compreensão de que o projeto de grandes empresas para o impulso das fontes formais autônomas alicerça-se na visão empreendedora de custo-benefício das multinacionais. Melhor dizendo, a institucionalização da iniciativa privada em determinado setor, in casu da mineração, engloba multifatores que se convergem na mesma operação matemática. De um lado, o nivelamento de práticas empresariais que lidam com as externalidades ambientais emparelha os custos das corporações concorrentes em um ramo de mercado e, de outro, boas práticas socioambientais alavancam a imagem e governança das organizações perante os consumidores, comunidade e Administração Pública, valor econômico inquestionável no cenário competitivo e regulatório atual.

Essencial o comento de que essas fontes formais regulatórias, via institucionalização e organização da iniciativa privada, não são incorporadas ao sistema jurídico nacional, como ocorre com as convenções e acordos coletivos na seara trabalhista. Todavia, a autorregulação ambiental em países como o Brasil, o qual legitima, apenas, uma atuação institucional da iniciativa privada em acordo com os parâmetros regulatórios do Estado, determina-se valiosa para a combinação de aspectos que envolvem a atividade minerária.

Essa assertiva respalda-se no fato de que, uma vez retirada a possibilidade de uma autorregulação mais flexível pelo setor econômico, bem como a inadmissão de integração jurídica da normatização produzida pelos atores da iniciativa privada, a institucionalização do setor minerário para a homogeneização de práticas corporativas e sustentáveis justifica-se se feita com base em parâmetros mais rígidos do que a regulação pública. Sob outro enfoque, a internalização e a constituição de protocolos de operação do setor econômico enfraquecem o denominado "turismo de direitos", ou seja, a procura por Estados com regulação e fiscalização precárias para o desenvolvimento da atividade mineira. A formação de uma cultura corporativa protocolar, balizada em práticas mais harmônicas da indústria — publicadas, auditadas e monitoradas pela própria concorrência e pela sociedade - , desfavorece uma gestão privada fragmentada por localidade de atuação, dado ampliador da sustentabilidade econômica também em países com sistemas normativos debilitados.

Ao retomar o cenário nacional, percebe-se que o sistema regulatório organiza-se em fluxos e por uma estrutura de gamificação ${ }^{21}$, isto é, múltiplos agentes sociais — sociedade civil organizada, setor econômico, Estado, população em geral, organizações supranacionais — são responsáveis pela regulação e monitoração da atividade minerária brasileira; e esses mesmos atores atuam em colaboração para a resolução dos problemas mais complexos do setor de uma forma menos áspera e mais autômata.

Ao imprimir essa ideia, não se pretende afirmar que o monitoramento do sistema regulatório brasileiro, bem como as práticas de gestão das corporações mineiras, estão em satisfatória operatividade e razoável efetivação dos seus fins. Quer-se expor aqui a ideação de que a normatização e limitação legal da atividade minerária não é um fenômeno exógeno, originário da verticalidade do Estado na relação com os particulares. Ao contrário, propugna-se por asseverar que o fenômeno da regulação é encíclico, de interesse de todos os agentes, direta e indiretamente envolvidos, e promove-se pelo interesse e em prol de múltiplas utilidades, especialmente as econômicas.

18 A respeito das fontes formais no Direito do trabalho, consultar: CORREIA, Henrique. Direito do trabalho. 6. ed. Salvador: Juspodivm, 2015, p. 38.

19 A análise custo-benefício foi analisada por Sunstein com foco na atividade regulatória da Administração Pública americana. A respeito, ver: SUNSTEIN, Cass R. Simpler: the future of government. New York, NY: Simon and Schuster, 2014.

20 Ayres e Braithwaite, por sua vez, analisam a regulação responsiva da iniciativa privada - via autorregulação - também com o enfoque custo-benefício. A respeito, ver: AYRES, Ian; BRAITHWAITE, John. Responsive regulation. Transcending the deregulation debate. New York, NY: Oxford University, 1992. p. 16-19.

21 O termo "gamificação" é utilizado no trabalho como a aplicação da teoria atrativa dos jogos para a resolução de diversos problemas reais. 


\subsection{Sob o ponto de vista do estado}

Assente na compreensão de que o movimento regulatório retroalimenta-se e opera-se em benefício de todos, passa-se a uma análise mais detida da perspectiva estatal ao estabelecer a regulação ambiental sobre a atividade econômica de mineração.

Como já citado, a normatização ambiental no Brasil é de competência plural, de todos os entes da Federação e da sociedade civil. O compartilhamento de competências realiza-se intramuros, melhor dizendo, dentro da própria estrutura normatizadora operacionalizada pela máquina legislativa do Estado. A Política Nacional do Meio Ambiente (PNMA) ${ }^{22}$, ao estatuir o Conselho Nacional de Meio Ambiente (CONAMA) ${ }^{23}$, órgão consultivo e deliberativo do Sistema Nacional do Meio Ambiente (SISNAMA), investe-o de poderes normativos ${ }^{24}$, ao mesmo tempo que o estrutura de forma a abarcar um largo espectro de agentes públicos, das mais diversas áreas de atuação, bem como da sociedade civil organizada, tanto em sua vertente ambientalista como econômica ${ }^{25}$. Essa peculiaridade de composição e investidura promove o exercício da democracia representativa e direta de maneira integrada e simultânea e não disjuntiva, como, aparentemente, afigura-se na Constituição da República de $1988(\mathrm{CR} / 1988)^{26}$.

Um dos dados mais relevantes dessa elaboração encontra-se no realce de que o fluxo regulatório ambiental advém de uma construção comum, destituída do viés administrativo por meio do qual a supremacia do interesse público suplantaria a atuação do empresariado. Outro fato que se sobressai é a consternação do Estado brasileiro com o fortalecimento dos laços democráticos na regulação, promovendo uma combinação de autorregulação e corregulação inserta nas próprias disposições legais que regem o sistema normativo nacional. Segundo os estudos de Nusdeo $^{27}$, a utilização da estrutura atributiva de competências do próprio Estado para um comprometimento maior entre a população em geral, indústrias e Federação brasileira inaugura uma nova forma de normatizar, por meio do que $\operatorname{Nusdeo}^{28}$ denomina de "Direito Reflexivo".

Portanto, "regular", segundo o modelo normativo nacional de hoje, é propiciar a produção da norma, o que, também, modifica a forma de monitorar. Consequentemente, a fiscalização regulatória não se dá, majoritariamente, pelo exercício do poder de polícia da Administração Pública, mas pelos próprios sujeitos produtores da norma, os quais são numerosos e heterogêneos, cada qual formando, paralelamente ao Poder Público, instrumentos de acesso, verificação, auditoria e avaliação dos parâmetros normativos, bem como institucionalizando setores de interesse por meio de uma regulação ainda mais severa do que a emanada em conjunto com os agentes públicos.

A fiscalização indireta nada mais é do que um programa do próprio Estado, não é uma modalidade de monitoramento paralela, criada a partir do insucesso e insuficiência do poder de polícia tipicamente estatal.

Sunstein ${ }^{29}$, administrador do OIRA (White House Office of Information and Regulatory Affairs) durante o Governo Obama nos Estados Unidos, evidencia como o programa regulatório norte-americano foi simplificado ou mitigado pela oportunização de participação direta da população no sistema normativo americano, bem como pelo favorecimento, por parte do Estado, de uma arquitetura de escolha ${ }^{30}$ concedida ao particu-

22 Ver: Lei n ${ }^{\circ}$ 6.938/1981.

23 A respeito do Conselho Nacional do Meio Ambiente (CONAMA), ver: art. 6º inciso II, da Lei no 6.938/1981.

24 A respeito da competência normativa do CONAMA, consultar: art. $7^{\circ}$, incisos I, VI, VIII, IX, do Decreto-Lei no 99.274/1990.

25 A respeito da estrutura do CONAMA, consultar: art. $4^{\circ}$ a $6^{\circ}$ do Decreto-Lei $n^{\circ}$ 99.274/1990.

26 A respeito das modalidades de exercício da democracia, consultar: art. $1^{\circ}$, parágrafo único; art. $5^{\circ}$, inciso LXXIII, e art. 14, ambos da CR/1988.

27 NUSDEO, Fábio. Autorregulação em direito econômico. In: ACCIOLY, Elizabeth (Coord.). Direito no século XXI: em homenagem ao professor Werter Faria. Curitiba: Juruá, 2008. p. 163-175, p. 163.

28 NUSDEO, Fábio. Autorregulação em direito econômico. In: ACCIOLY, Elizabeth (Coord.). Direito no século XXI: em homenagem ao professor Werter Faria. Curitiba: Juruá, 2008. p. 163-175, p. 163.

29 SUNSTEIN, Cass R. Simpler: the future of government. New York, NY: Simon and Schuster, 2014. p. 209.

30 A respeito da choice architecture de Sunstein, consultar: SUNSTEIN, Cass R. Simpler: the future of government. New York, NY: 
lar, a qual maximizou o entendimento das políticas públicas, da normatização primária e secundária, assim como da fiscalização indireta das regras do jogo pela própria iniciativa privada.

No Brasil, esse planejamento não é diferente. O Estado brasileiro, ao regular o meio ambiente e a mineração de forma colaborativa, intenta, da mesma forma, criar um espaço próspero e conveniente à sociedade. A discrepância na efetividade e monitoramento regulatórios entre Brasil e Estados Unidos orienta-se pela conformação atual da democracia nacional, quebradiça e imiscuída em programas de governo e não em programas de Estado, aprofundamentos que não são objetos deste trabalho.

Por outro lado, a pulverização regulatória, parte do tema aqui proposto, granjeada com o desmembramento da estrutura regulatória ambiental entre os entes da Federação, acarreta, igualmente, uma conjuntura prejudicial à arquitetura de escolha de Sunstein ${ }^{31}$. Por "arquitetura de escolha" entenda-se o arranjo organizatório previamente estabelecido pelo Estado, para que a escolha das pessoas em relação aos assuntos mais pertinentes da vida em comunidade realmente lhes traga benefícios individuais e coletivos. Dessarte, a Federação brasileira, ao regular o meio ambiente, investiga e pondera qual a melhor forma de estabelecimento da ordem regulatória para que os próprios destinatários dela possam, natural e livremente, optar pelo cumprimento, monitoramento e participação na construção da rede normativa.

Importante a menção de que a já discutida participação dos múltiplos segmentos da sociedade no SISNAMA não é o ponto que se analisa com essa digressão. $\mathrm{O}$ aspecto suscitado nessa consideração refere-se à possibilidade de normatização ambiental pela União, Estados, Distrito Federal (DF) e Municípios, concomitantemente.

As prescrições da CR/1988 outorgam uma ampla simbiose regulatória entre as três esferas de governo, já que a suplementação de normas gerais pelos Estados e Distrito Federal (DF) ${ }^{32}$ consubstanciam-se por uma atividade de largo preenchimento conteudista à legislação da União, assim como a suplementação legislativa municipal, associada à plena competência normativa para assuntos locais ${ }^{33}$, inspiram parcialidade quanto à aferição de limites de atribuição entre as pessoas jurídicas de direito público interno.

Essa concepção acarreta um sistema jurídico ambiental complexo, por camadas, dividido em porções que muitas vezes não se concertam em um todo inteligível e de fácil reconhecimento. Assim, a "arquitetura de escolha", ao tempo que é impulsionada pela infiltração da sociedade nos assuntos de Estado — competência normativa —, é infirmada pela difícil assimilação da intensa e cindida produção regulatória.

Os trabalhos de economia comportamental de Sunstein ${ }^{34}$ sustentam a eminência da simplicidade no ato de regular para a pronta e ágil apreensão da matéria regulada, atributo que a regulação ambiental nacional não ostenta. Desse modo, a funcionalidade do esqueleto normativo para a impregnância da regulação ampla participação, compliance ${ }^{35}$ e ampla fiscalização indireta — torna-se muito custosa na avaliação das pessoas e dos grupos civis organizados. A aferição custo-benefício para o desempenho das atividades que a arquitetura de escolha almeja, qual seja, sujeição e monitoramento contínuos para o desinchamento das atribuições estatais, revela-se dispendiosa nas operações mentais das pessoas para iniciar ou motivar suas ações.

Essas apreciações levam à conclusão de que o Brasil possui uma análise estatal de política pública regulatória paradoxal — avançada em alguns pontos e incompetente em outros. A combinação dessa contradição é nada mais do que um sistema regulatório inábil, vicioso e propenso a favorecer o comportamento de neutralidade crítico das pessoas, ou seja, nada fazem para implementar, aprimorar e controlar a regulação

Simon and Schuster, 2014. p. 8-10.

31 SUNSTEIN, Cass R. Simpler: the future of government. New York, NY: Simon and Schuster, 2014. p. 8-10.

32 A respeito, ver: art. 24 da CR/1988.

33 A respeito da competência legislativa municipal, consultar: art. 30, incisos I e II, da CR/1988.

34 Para aprofundamento, ver: SUNSTEIN, Cass R. Simpler: the future of government. New York, NY: Simon and Schuster, 2014.

35 Por compliance, entenda-se a sujeição à regulação ambiental pelo alargamento da fiscalidade nos processos internos das corporações. 
posta, ao mesmo tempo que responsabilizam o Estado por todas as externalidades ambientais sofridas ou esperadas.

\subsection{Sob o ponto de vista dos atores sociais}

Por sua vez, os atores da sociedade ${ }^{36}$, principalmente as empresas mineradoras, as quais se beneficiam ou se prejudicam pelas políticas públicas estatais e enfrentam, ao mesmo tempo, as vicissitudes do pano de fundo formador da organização social, mantêm a posição de análise econômica dos dilemas da atividade mineradora.

O licenciamento ambiental ${ }^{37}$ na conjuntura brasileira é um dos mais expressivos mecanismos de gestão regulatória da atualidade. A operacionalização de seus fins, no entanto, só efetivar-se-á caso a iniciativa privada o implemente maciçamente.

Como é cediço, o licenciamento ambiental é um procedimento administrativo único, dividido em etapas que se condicionam às posteriores em um concatenamento avaliativo dos impactos negativos, viabilidade econômica, prevenção e implementação de medidas mitigadoras. O procedimento é extenso, demanda criteriosa análise e dedicação de tempo, tanto da Administração Pública quanto do particular — empresas e população em geral.

Assim, na realidade econômica global, de dominação de grandes consórcios mineradores na atividade mineira mundial e de ampliação dos requerimentos de concessão de aproveitamento mineral e de pedidos de licenciamento ambiental no Brasil, pensar que a Administração Pública manejará formas de avaliação analítica, de monitoramento e controle eficazes de todas as atividades de impacto ambiental é uma expectativa ingênua e inviável.

O procedimento de licenciamento ambiental, na sua orientação burocrática e protocolar, já não é de fácil sujeição. O labor corporativo de elaboração e corporificação da documentação necessária durante todo o processo demanda um considerável investimento financeiro, de força de vontade e organização empresarial. À população interessada e sociedade civil em geral, em igual modo, não se revela descomplicado. O acesso, a participação e a concreta persuasão dos atores diretamente envolvidos demandam bastante engajamento, empenho que, muitas vezes, é considerado inútil na avaliação singular e conjunta dos cidadãos.

E isso é só durante o desenvolvimento do curso procedimental. Trabalho muito mais árduo dá-se como a real execução dos programas descritos nos estudos, planos, programas, avaliações, relatórios e termos de compromisso ali firmados, bem como na fiscalização indireta, leia-se, pela própria sociedade, quanto aos requisitos, condicionantes e obrigações criados.

Sob esse enfoque e nas atuais conjecturas, a consumação da papelada, seja física ou digital, do licenciamento ambiental, é muito pouco atrativa para a iniciativa privada e sociedade. Para o Estado, representado por sua Administração Pública, é, matematicamente, impossível.

A visão de custo-benefício de implementação real das disposições insertas no procedimento acaba por impelir ações afirmativas apenas em resposta a outras ações esporádicas dos demais setores envolvidos na questão, como a atuação do Ministério Público (MP) decorrente de representações específicas, da atividade fiscalizatória por amostragem, do benchmarking ${ }^{38}$ de demais empresas concorrentes, da atuação setorizada de um determinado grupo da sociedade civil diretamente interessado, de pressões política, enfim, são empreendimentos segmentados de reação e não de sólida implantação da normatividade imposta e criada.

36 Por "atores da sociedade", entenda-se o segundo e terceiros setor, bem como a população em geral.

37 A respeito do licenciamento ambiental, consultar: arts. 17 a 19 do Decreto-Lei no 99.274/1990.

38 Benchmarking deve ser compreendido como um instrumento de avaliação das corporações através de estudos comparativos com as demais empresas insertas em um mesmo setor econômico de atuação. 
Isto posto, se ao procedimento de licenciamento ambiental não é cabível uma simplicidade elaborativa como proposta no trabalho de Sunstein ${ }^{39}$, já que envolve uma seriação de diagnósticos técnicos e de avaliações profissionais especializadas, uma arquitetura mais cômoda e simpatizante à iniciativa privada deve ser colocada em pauta em relação ao licenciamento ambiental.

O cumprimento, não apenas dos compromissos do licenciamento como também da fiscalização indireta e de todas as ações de cunho mais restritivo do que os parâmetros da legislação estatal — como a institucionalização da iniciativa privada em busca de homogeneização de custos e práticas no mercado concorrencial —, somente será exitoso se a armação estrutural for amigável, ou seja, o sistema protocolar deve ser receptível a mudanças, deve ter autonomia de eliminar disposições regulatórias que no presente não fazem mais sentido, deve incentivar a integração com os demais sistemas regulatórios de sucesso no mundo, deve centrar-se em exigências regulatórias apolíticas e priorizar ações reais a preenchimento de requisitos oficiais.

Reduzir a burocracia e o preenchimento de protocolos documentais não significa desregular a atividade de impacto ambiental, mas salvar energia da iniciativa privada para a efetivação de ações afirmativas que, realmente, farão diferença e previnirão desastrosas externalidades negativas.

\section{A CONSTRUÇÃo PROCESSUAl PARA A FiscalidAde democrática: ANÁlISE dE COMPLIANCE MINERÁRIO}

Esse panorama de avaliação custo-benefício é multidimensional, isto é, ocorre em todos os setores da sociedade e do governo. Por mais que a regulação ambiental brasileira atual não esteja condizente com a ciência comportamental natural dos seres humanos e vise a propulsionar um "dever-ser regulatório", em se tratando de atividades de altíssimo impacto ambiental como a atividade de mineração, o "dever-ser" acaba por engessar a fluidez de um sistema que pode se autoaprimorar, refazer-se e se reelaborar para tornar a vida das pessoas melhor.

Se, intuitivamente, a sociedade aspira por uma regulação ampla do meio ambiente por parte do Estado, por uma fiscalização densa e por leis cada vez mais restritivas, na prática, essa idealização não se revela pertinente em razão dos altos custos e escassas benesses tangíveis a olho nu ou em um período de tempo que se possa considerar como atual.

Por essas razões, a regulação responsiva de Ayres e Braithwaite ${ }^{40}$ é aquela que, naturalmente, se emerge $e^{41}$ a partir da intensificação de laços entre setores sociais vários e desiguais, considerando-se que essa naturalidade perfaz-se com a concretude da aplicação do que foi previamente posto. Entre agir e desistir, os atores sociais escolhem por agir, não porque deve ser, mas por ser mais benéfico se comparado ao proveito da inação.

À vista disso, o panorama privatístico sustentador da atividade regulatória participativa da sociedade brasileira padece de boas perspectivas econômicas. A análise formal empresarial e intuitiva da sociedade civil dos custos e benefícios que o licenciamento ambiental traz decompõe-se em dupla orientação: a orientação comportamental frágil e a orientação deôntica fictícia idealizada. Essa disjunção não consegue traçar pontos de identificação ou união, mas proporciona a perpetuação da inação, da insatisfação, do gasto excessivo de energia e pecúnia e do mais caótico desfecho: o perdimento de vidas e a extenuação dos recursos naturais.

Propõe-se, assim, uma reformatação da maneira como se instrumentaliza a metodologia normativa de

39 Conforme: SUNSTEIN, Cass R. Simpler: the future of government. New York, NY: Simon and Schuster, 2014.

40 Conforme conceito de AYRES, Ian; BRAITHWAITE, John. Responsive regulation. Transcending the deregulation debate. New York, NY: Oxford University, 1992. p. 16-19.

41 A respeito, consultar: AYRES, Ian; BRAITHWAITE, John. Responsive regulation. Transcending the deregulation debate. New York, NY: Oxford University, 1992. p. 16-19. 
efetivação do direito fundamental ao meio ambiente equilibrado. Primeiramente, a estruturação do CONAMA não deve ser presumida como democrática, apesar da participação de representantes de todas as esferas do Poder Público, da sociedade civil e do empresariado. Deve-se ter em mente que a nomeação e os critérios de escolha dos componentes do CONAMA são de competência do Poder Executivo, não havendo qualquer tipo de escrutínio popular ou requisitos transparentes de escolha que impliquem uma vinculação objetiva para a nomeação desses representantes.

Dessa forma, a regulação produzida pelo órgão não é, necessariamente, responsiva e não pode, a priori, deduzir-se que esta foi elaborada em um ambiente de fortalecimento das discussões e da informação acerca dos objetivos e demandas regulatórias. Inúmeras teorias da regulação $\mathrm{O}^{42}$ de origem estrangeira intentam esclarecer os modos pelos quais a regulação produzida pela Administração Pública pode ser "capturada" em função dos interesses econômicos dos grupos mais poderosos da sociedade. Portanto, há que se construir um critério claro e legítimo de escolha e nomeação dos representantes do conselho regulador, bem como criar demais mecanismos de abertura desses conselhos à participatividade difusa ${ }^{43}$.

Em relação a esses mecanismos de abertura alternativos, Sustein ${ }^{44}$ revela que, no Direito americano, durante sua gestão do OIRA, foi implementada a obrigatoriedade da Administração Pública em colocar a regulação que se pretendia instituir a exame público prévio, ou seja, dava-se ampla publicidade prévia às pretensões normativas e, a cada sugestão ou crítica da população ou dos setores organizados a esta, havia o dever inequívoco de responder ao cidadão, esclarecendo-lhe as razões de acatamento ou não de suas contribuições aos atos administrativos normativos.

Essa política de retorno motivado ${ }^{45}$ ao cidadão foi capaz de propiciar à Administração Pública a oportunidade de ouvir e de ser influenciada, efetivamente, pela sociedade, reformulando e reconstruindo a regulação para que ela fosse mais clara, mais simples, mais legítima e mais bem recepcionada pela população. Atualmente, no Brasil, o acesso à informação ${ }^{46}$ é, normativamente, instituído, mas a sua operacionalidade ainda é precária. A Administração Pública é lenta em prover a informação e, acima de tudo, não há a obrigatoriedade de submissão das normas ditas "secundárias" de serem, previamente, colocadas em pauta para discussão ampla e efetivação das reformas necessárias anteriormente à sua vigência.

Todas essas peculiaridades do sistema nacional estão, intimamente, relacionadas à carência de um processo administrativo normativo preestabelecido, que institua, democraticamente, desde os critérios de escolha e nomeação dos representantes dos conselhos do Poder Público até a metodologia de fiscalidade prévia de cada norma que se pretende colocar em vigor.

A construção de uma estrutura técnica procedimental de efetivação da fiscalidade normativa na Administração Pública é uma reforma fulcral que favorecerá todos os instrumentos de controle e preservação ambiental, já que abrirá concretamente os muros do Poder Público para uma ampla reflexividade, mitigando as "capturas" predominantes da regulação brasileira e trazendo ao licenciamento ambiental uma maior racionalidade, acatamento e controle.

42 A respeito, consultar: LOSS, R. Giovani. Contribuições à teoria da regulação no Brasil: fundamentos, princípios e limites do poder regulatório das agências. In: ARAGÃO, Alexandre Santos de (Coord.). O poder normativo das agências reguladoras. 2. ed. Rio de Janeiro: Forense, 2011. p. 109-130.

43 Em sentido equivalente: ARAUJO, Thiago Souza; SILVA, Kinn Peduti de Araujo Balesteros da; ROVER, Aires Jose. Gestão pública e parcerias público-privadas: teoria do estado e tecnologias de governança difusa para controle social. Revista Brasileira de Políticas Públicas (Online), Brasília, v. 6, n. 3, p. 65-89, set./dez. 2016. p. 66 e p. 74-75.

44 Para aprofundamento, ver: SUNSTEIN, Cass R. Simpler: the future of government. New York, NY: Simon and Schuster, 2014.

45 A motivação a que se faz referência deve, obrigatoriamente, ser uma motivação específica e elaborada de forma a justificar, pormenorizadamente, as razões de acatamento ou não da sugestão ou crítica do cidadão.

46 A respeito, consultar: Lei $n^{\circ} 12.527 / 2011$ 


\section{Considerações Finais}

O presente artigo procurou trazer uma percepção reformista da sistemática regulatória ambiental aplicada à atividade mineira no intuito de alevantar o pensamento sobre a arquitetura de escolha, outrora apresentada neste estudo.

O sistema regulatório contemporâneo implica uma análise prévia, concomitante e ulterior acerca de todos os aspectos que envolvem a regulação. Regular transcende, em muito, a concepção de impor parâmetros e limitações de atuação aos agentes socioeconômicos.

Envolve a investigação da natureza do comportamento humano, suas motivações, causas e análises de foro íntimo a respeito do custo-benefício da ação e da inação. Abarca um estudo minucioso atinente à participatividade da iniciativa privada que deve ser o motor principal do sistema regulatório na formação da norma, na fiscalização e controle da impregnância e viabilidade da regulação, dos índices de receptividade e compliance e, principalmente, da expectativa de exequibilidade da regulação no cotidiano real das pessoas e da sociedade em geral.

O sistema regulatório brasileiro deve ser decifrado como cíclico e as fontes alimentantes e retroalimentantes nessa conjuntura necessitam de aptidão para a averiguação socioambiental da normatividade. Estado, população, segundo setor, sociedade civil organizada, organizações supranacionais, mídia e demais nações têm de tomar as rédeas do sistema regulatório contemporâneo, empreendendo a checagem acerca da facilidade, simplicidade e naturalidade do sistema jurídico.

A regulação ambiental em tela é uma obra criada por todos, em prol de todos, e não se organiza sob comandos imperativos exógenos derivativos de um poder supremo e dotado de prerrogativas inoperantes nas relações privatísticas. A todos os atores sociais é demandada essa consciência.

A regulação responsiva e a arquitetura de escolha propiciam questionamentos concernentes à regulação ambiental brasileira, "pretensamente" avançada sob o prisma de infiltração maciça de segmentos sociais vários na gênese normativa, mas, por outro lado, determinante de múltiplas fontes formais produtoras de normas, em contextos e âmbitos diversos, além da estruturação de um numeroso aparato setorizado de gestão ambiental, fato que favorece uma disjunção complexa, pouco intuitiva e de custos elevados de operatividade e concretude.

A visão estatal e dos atores sociais, principalmente dos agentes econômicos, foi o foco deste trabalho, justamente ao escopo de que o leitor analise a atividade regulatória levando-se em conta os divergentes e convergentes pontos de vista para um maior proveito de efetividade, salvaguarda de vidas, proteção ambiental e economicidade.

Portanto, a partir dessas digressões, faz-se essencial enxergar o sistema regulatório ambiental como um instituto fluido, que mitiga as barreiras entre público-privado e posiciona a sociedade na autoridade maior de condução do seu próprio sistema jurídico, bem como do seu desfecho exitoso ou adverso.

As características do sistema constitucional nacional referentes à regulação e gestão ambientais dessa política normativa, assim como os atributos, custos, benefícios e condições de realização dos planos e compromissos firmados na criação de uma metodologia normativa de proteção ambiental, constituem a pedra de toque para o prelúdio de uma reformatação regulatória ambiental voltada à atividade mineira.

Paralelamente, a coexistência de regramentos autônomos advindos precipuamente do setor minerário é importante ferramenta para a formação de uma cultura de boas práticas empresariais, articuladora de uma condução dos negócios minerários segundo as melhores evidências científicas e técnicas de segurança e sustentabilidade.

Portanto, uma maior integração e racionalidade da regulação ambiental minerária, bem como a imple- 
mentação de uma estrutura técnica normativa oportunizadora da efetividade dos direitos e garantias fundamentais ambientais na condução da atividade mineira, constituem referências importantes para a ampliação de compliance regulatória, inaugurando uma política pública de economia comportamental que atenda mais adequadamente a dinâmica social ambiental brasileira, extremamente dependente e penalizada pelas externalidades da atividade econômica minerária.

\section{REFERÊNCIAS BIBLIOGRÁFICAS}

ARAUJO, Thiago Souza; SILVA, Kinn Peduti de Araujo Balesteros da; ROVER, Aires Jose. Gestão pública e parcerias público-privadas: teoria do estado e tecnologias de governança difusa para controle social. Revista Brasileira de Políticas Públicas (Online), Brasília, v. 6, n. 3, p. 65-89, set./dez. 2016. Disponível em: <https:// www.publicacoesacademicas.uniceub.br/RBPP/article/view/4262>. Acesso em: 10 abr. 2017.

AYRES, Ian; BRAITHWAITE, John. Responsive regulation. Transcending the deregulation debate. New York, NY: Oxford University, 1992.

BIZAWU, Kiwonghi; GOMES, Magno Federici. Oil exploitation at Virunga park as a threat to the environment and to endangered animal species. Veredas do Direito, Belo Horizonte, v. 13, n. 27, p. 11-29, set./ dez. 2016. Disponível em: <http://www.domhelder.edu.br/revista/index.php/veredas/article/view/897>. Acesso em: 19 jan. 2017.

BRASIL. Constituição da República Federativa do Brasil de 1988. Diário Oficial, Brasilia, 05 out. 1988. Disponível em: <http://www.planalto.gov.br>. Acesso em: 19 jan. 2017.

BRASIL. Decreto-Lei no 227, de 28 fev. 1967. Dá nova redação ao Decreto-Lei no 1.985, de 29 de janeiro de 1940. (Código de Minas). Diário Oficial, Brasília, 28 fev. 1967. Disponível em: <http://www.planalto.gov. br>. Acesso em: 19 jan. 2017.

BRASIL. Decreto-Lei no 99.274, de 06 jun. 1990. Regulamenta a Lei nº 6.902, de 27 de abril de 1981, e a Lei n 6.938, de 31 de agosto de 1981, que dispõem, respectivamente sobre a criação de Estações Ecológicas e Áreas de Proteção Ambiental e sobre a Política Nacional do Meio Ambiente, e dá outras providências. Diário Oficial, Brasília, 07 jun. 1990. Disponível em: <http://www.planalto.gov.br>. Acesso em: 19 jan. 2017.

BRASIL. Lei Complementar (LC) no 140, de 08 dez. 2011. Fixa normas, nos termos dos incisos III, VI e VII do caput e do parágrafo único do art. 23 da Constituição Federal, para a cooperação entre a União, os Estados, o Distrito Federal e os Municípios nas ações administrativas decorrentes do exercício da competência comum relativas à proteção das paisagens naturais notáveis, à proteção do meio ambiente, ao combate à poluição em qualquer de suas formas e à preservação das florestas, da fauna e da flora; e altera a Lei $\mathrm{n}^{\circ}$ 6.938, de 31 de agosto de 1981. Diário Oficial, Brasília, 09 dez. 2011. Disponível em: <http://planalto.gov. br>. Acesso em: 19 jan. 2017.

BRASIL. Lei no 12.527, de 18 nov. 2011. Regula o acesso a informações previsto no inciso XXXIII do art. $5^{\circ}$, no inciso II do $\int 3^{\circ}$ do art. 37 e no $\ 2^{\circ}$ do art. 216 da Constituição Federal; altera a Lei no 8.112 , de 11 de dezembro de 1990; revoga a Lei no 1.111, de 5 de maio de 2005, e dispositivos da Lei no 8.159, de 8 de janeiro de 1991; e dá outras providências. Diário Oficial, Brasilia, 18 nov. 2011. Disponível em: <http://planalto.gov. br>. Acesso em: 19 jan. 2017.

BRASIL. Lei n ${ }^{\circ}$ 6.938, de 31 ago. 1981. Dispõe sobre a Política Nacional do Meio Ambiente, seus fins e mecanismos de formulação e aplicação, e dá outras providências. Diário Oficial, Brasília, 02 set. 1981. Disponível em: <http://planalto.gov.br>. Acesso em: 19 jan. 2017.

BRASIL. Lei n 8.876, de 02 maio 1994. Autoriza o Poder Executivo a instituir como Autarquia o Depar- 
tamento Nacional de Produção Mineral (DNPM), e dá outras providências. Diário Oficial, Brasília, 03 maio 1994. Disponível em: <http://planalto.gov.br>. Acesso em: 19 jan. 2017.

CORREIA, Henrique. Direito do trabalho. 6. ed. Salvador: Juspodivm, 2015.

DISTRITO FEDERAL. Instituto Brasileiro de Mineração (IBRAM). Disponível em: < http://www.ibram.org. br>. Acesso em: 19 jan. 2017.

DWORKIN, Ronald. O império do direito. 3. ed. Tradução de Jefferson Luiz Camargo. São Paulo: Martins, 2014.

ESTADOS UNIDOS DA AMERICA. White House Office of Information and Regulatory Affairs (OIRA). Disponível em: <https://www.whitehouse.gov/omb/oira>. Acesso em: 19 jan. 2017.

FARIAS, Talden. Licenciamento ambiental. Aspectos teóricos e práticos. Belo Horizonte: Fórum, 2013.

INGLATERRA. Conselho Internacional de Mineração e Metais (DNPM). Disponível em: < http://www.icmm. com>. Acesso em: 19 jan. 2017.

JOERGES, Christian. Juridification Patterns for Social Regulation and the WTO: A Theoretical Framework. TranState Working Papers, Bremen: Sfb 597, Staatlichkeit im Wandel, n. 17, p. 1-42, jan. 2005. Disponível em: <https://papers.ssrn.com/sol3/papers.cfm?abstract_id=2155825>. Acesso em: 19 jan. 2017.

LOSS, R., Giovani. Contribuições à teoria da regulação no Brasil: fundamentos, princípios e limites do poder regulatório das agências. In: ARAGÃO, Alexandre Santos de (Coord.). O poder normativo das agências reguladoras. 2. ed. Rio de Janeiro: Forense, 2011. p. 109-130.

MARINELA, Fernanda. Direito administrativo. 7. ed. Niterói: Ímpetos, 2013.

MATTOS, Paulo Todescan Lessa. Regulação econômica e democracia: contexto e perspectivas na compreensão das agências de regulação no Brasil. In: FARIA, José Eduardo (Org.). Regulação, direito e democracia. São Paulo: Fundação Perseu Abramo, 2002. p. 43-66.

MELLO, Celso Antônio Bandeira de. Curso de direito administrativo. 29. ed. São Paulo: Malheiros, 2012.

MOREIRA NETO, Diogo de Figueiredo. Mutações do direito administrativo. Rio de Janeiro: Renovar, 2007.

NUSDEO, Fábio. Autorregulação em direito econômico. In: ACCIOLY, Elizabeth (Coord.). Direito no século XXI: em homenagem ao professor Werter Faria. Curitiba: Juruá, 2008. p. 163-175.

SERRA, Silvia Helena. Direitos minerários: formação, condicionamentos e extinção. São Paulo: Signus, 2000.

SERRA, Silvia Helena; ESTEVES, Cristina Campos. Mineração: doutrina, jurisprudência, legislação e regulação setorial. São Paulo: Saraiva, 2012. (Col. Direito Econômico).

SOLOMON, Jason M. New governance, Preemptive self-regulation, and the blurring boundaries in regulatory theory and practice. Wisconsin Law Review, Madison-USA, p. 9-69, jul. 2010. Disponível em: < http:// papers.ssrn.com/sol3/papers.cfm?abstract_id=1758746>. Acesso em: 19 jan. 2017.

SUNSTEIN, Cass R. A constitution of many minds: why the founding document doesn't mean what it meant before. New Jersey: Princeton University, 2009.

SUNSTEIN, Cass R. Simpler: the future of government. New York, NY: Simon and Schuster, 2014.

Agradecimentos: Trabalho financiado pelo Edital no 05/2016 (Projeto no FIP 2016/11173-S2) do FIP/ PUC, resultante dos Grupos de Pesquisas (CNPq): Regulação Ambiental da Atividade Econômica Sustentável (REGA) e CEDIS (FCT-PT). 
Para publicar na revista Brasileira de Políticas Públicas, acesse o endereço eletrônico www.rbpp.uniceub.br

Observe as normas de publicação, para facilitar e agilizar o trabalho de edição. 